\title{
Long-term angiographic results of endovascularly "cured" intracranial dural arteriovenous fistulas
}

\author{
Sudheer Ambekar, MD, Brandon G. Gaynor, MD, Eric C. Peterson, MD, and \\ Mohamed Samy Elhammady, MD
}

\begin{abstract}
Division of Endovascular Neurosurgery, Department of Neurological Surgery, University of Miami Miller School of Medicine, Miami, Florida
\end{abstract}

\begin{abstract}
OBJECTIVE Dural arteriovenous fistulas (DAVFs) are complex lesions consisting of abnormal connections between meningeal arteries and dural venous sinuses and/or cerebral veins. The goal of treatment is surgical or endovascular occlusion of the fistula or fistulous nidus or at least the disconnection of the feeding vessels and the draining veins. Delayed angiographic data on previously embolized dural fistulas is lacking. The authors report their experience and the long-term angiographic results with embolization of intracranial DAVF using Onyx.
\end{abstract}

METHODS All cases of DAVF treated primarily with Onyx at the authors' institution from 2006 to 2013 were retrospectively reviewed. Patient demographics, fistula characteristics, embolization details, and angiographic follow-up were analyzed.

RESULTS Fifty-eight patients with DAVFs were treated during the study period. Twenty-two patients were treated with open surgery with or without prior embolization. Thirty-six patients were treated with embolization alone, of whom 26 underwent an attempt at curative embolization and are the subject of this review. All but 2 of these patients were treated in a single session. Angiographic "cure" was achieved in all cases following treatment. Follow-up angiography was performed in 21 patients at a mean of 14 months after treatment (range 2-39 months). Asymptomatic angiographic recurrence of the fistula was evident in 3 of the 21 patients (14.3\%). On reviewing the procedural angiograms of the cases in which the DAVFs recurred, it was observed that the Onyx cast did not reach the venous portion in 1 case, whereas it did reach the vein in the other 2 cases.

CONCLUSIONS Recurrence following initial angiographic cure of DAVF is not uncommon. Incomplete penetration of the embolic material into the proximal portion of the venous outlet may lead to delayed recurrence. Long-term angiographic follow-up is highly recommended.

http://thejns.org/doi/abs/10.3171/2015.3.JNS1558

KEY WORDS fistula; intracranial; dural; arteriovenous; embolization; recurrence; vascular disorders

$\mathrm{D}$ URAL arteriovenous fistulas (DAVFs) are abnormal communications between dural arteries and dural venous sinuses or subarachnoid veins and account for approximately $10 \%-15 \%$ of all intracranial vascular malformations. ${ }^{11}$

Treatment of these lesions is based on the presenting symptoms and the presence of cortical venous reflux. The goal of treatment is surgical or endovascular occlusion of the fistula or fistulous nidus or at least the disconnection of the feeding vessels and the draining veins. Embolization of DAVFs can be achieved using a variety of embolic agents. Onyx (ethylene vinyl alcohol, ev3) was FDA ap- proved in 2005 for preoperative embolization of cerebral arteriovenous malformations (AVMs), and has since been successfully used to treat other vascular lesions such as spinal AVMs and cerebral DAVFs as well as various tumors. ${ }^{8}$ Although, endovascular "cure" of cerebral DAVFs using Onyx has been reported by multiple centers, the incidence of recurrence following initial angiographic obliteration has not been well established..$^{1,7,9,12}$ In this article, we present a series of patients with cerebral DAVFs who underwent endovascular embolization with a curative intent. Our aim was to study the incidence and the factors affecting recurrence.

ABBREVIATIONS AVM = arteriovenous malformation; $C V D=$ cortical venous drainage; $D A V F=$ dural arteriovenous fistula; $S R S=$ stereotactic radiosurgery .

SUBMITTED January 9, 2015. ACCEPTED March 30, 2015.

INCLUDE WHEN CITING Published online September 25, 2015; DOI: 10.3171/2015.3.JNS1558. 


\section{Methods}

The Institutional Review Board at the University of Miami Miller School of Medicine approved this study. The database of neuroendovascular cases was searched retrospectively to identify cases of cranial DAVFs treated with Onyx during the time period from 2006 to 2013 . Patients with carotid cavernous fistulas, with DAVFs who underwent stand-alone surgical treatment or combined endovascular and surgical treatment, or with DAVFs who underwent palliative embolization were excluded. Patient demographics, fistula characteristics, and procedural angiograms as well as follow-up angiograms were analyzed. The decision to perform a follow-up angiogram was at the discretion of the treating physician. "Angiographic cure" was attempted in all patients and was defined as occlusion of the fistula and absence of early filling of its venous drainage. Determination of whether the embolic material reached the common draining venous outlet was made by evaluation of both the pre- and postembolization angiograms as well as the final Onyx cast.

\section{Results}

A total of 58 patients with cerebral DAVFs were treated at our institution from 2006 to 2013 . Of these, 26 patients underwent endovascular embolization with the intention of complete angiographic cure. The breakdown of cases according to mode of treatment is displayed in Fig. 1. A summary of the patient characteristics is provided in Table 1. The mean age at presentation was 55.4 years (range 6 months -83 years). There were 15 males and 11 females. Clinical presentation included intraparenchymal hemorrhage in 6 patients (23\%); pulsatile tinnitus in 4 patients (15\%); and ataxia, headache, dizziness, proptosis, myelopathy, subdural hematoma, and subarachnoid hemorrhage in 1 patient each. DAVFs were incidentally detected in 9 of the 26 patients (34.6\%). All procedures were completed in 1 session, except in 2 cases, which required 2 sessions of embolization to achieve angiographic cure.

The mean clinical follow-up was 15 months (2-39 months). Of the 13 patients with symptomatic presentation, clinical follow-up was available for 9. Improvement of symptoms was noted in 6 of the 9 patients (66.66\%), and symptoms were stable in 2 patients (22.2\%). One pa-

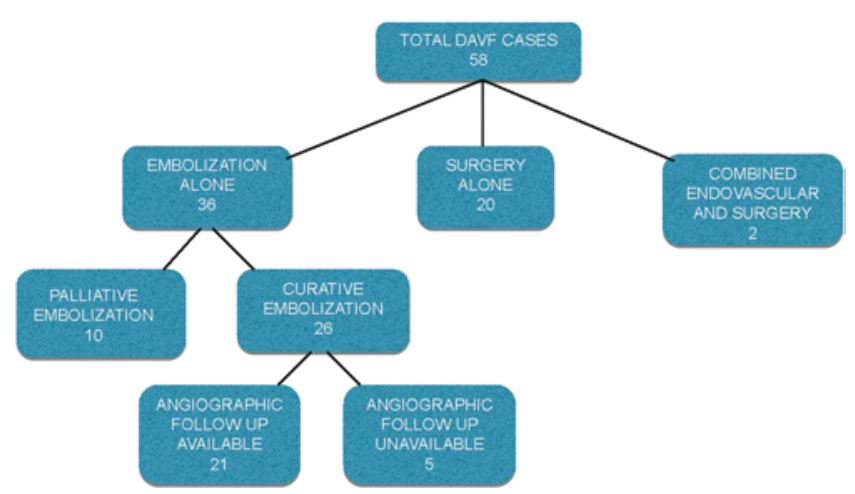

FIG. 1. Schematic showing the breakdown of patients according to treatment mode. Figure is available in color online only. tient who presented with a ruptured DAVF with a large subdural hematoma worsened to persistent vegetative state despite evacuation of the hematoma.

Follow-up angiography was performed in 21 (80.7\%) of 26 patients at a mean of 14 months after treatment (range 2-39 months). Recurrence of the fistula occurred in 3 (14.3\%) of the 21 patients at a mean duration of 18 months after embolization. Upon careful review of the procedural angiograms, we noted that the Onyx cast had not reached the proximal portion of the venous outlet in 1 patient, but it did reach the draining vein in the other 2 cases (Fig. 2). Of these 3 patients with recurrence, 1 patient underwent radiosurgery, and the other 2 patients were observed closely as there was no cortical venous reflux.

Nine patients in the present series had an angiographic follow-up of 12 or more months. Recurrence of the fistula occurred in 2 patients (22\%) at a mean duration of 24 months after embolization. The probability of recurrence was plotted against time in a Kaplan-Meier graph (Fig. 3). It shows that the probability of recurrence of the fistula is high in the 1st year after treatment, beyond which the probability of recurrence steeply decreases and is very low after 24 months of treatment.

\section{Discussion}

The natural history of cranial DAVFs has been shown to be associated with 3 factors: presence of cortical venous drainage (CVD), mode of presentation, and presence of other high-risk angiographic features. Type III DAVFs in the Borden-Shucart classification system ${ }^{3}$ and Types III, IV, and V in the Cognard ${ }^{6}$ system are associated with CVD and are more likely to be symptomatic. Intracranial hemorrhage is believed to result from rupture of fragile veins subjected to cortical venous hypertension. On the other hand, nonhemorrhagic symptoms result from venous congestion and cerebral ischemia. ${ }^{13,14}$ Mode of presentation and the location of DAVF are closely related. Anterior cranial fossa DAVFs often present with hemorrhage since they almost always have CVD. However, they can also present with proptosis and chemosis if they drain into the cavernous sinus. Middle fossa fistulas are more likely to present with pulsatile tinnitus due to increased drainage through the sigmoid and transverse sinuses. Tentorial DAVFs have also been observed to carry a high risk of intracerebral hemorrhage, again, because they almost always have CVD. Brainstem and superior sagittal sinus DAVFs are more likely to present with nonhemorrhagic neurological deficits such as quadriparesis and lower cranial nerve palsies in the former and hydrocephalus, papilledema, seizures, and dementia in the latter. ${ }^{14}$ Leptomeningeal drainage, variceal or aneurysmal venous dilatations, galenic drainage, and DAVFs of the petrosal and straight sinus have all been shown to carry a high risk of intracerebral hemorrhage, although this has not been validated in larger studies. ${ }^{2,4}$ Zipfel et al., in a systematic review, observed that symptomatic DAVFs have a high risk of intracerebral hemorrhage and death as compared with asymptomatic DAVFs. They concluded that Borden-Shucart Type I DAVFs without any CVD have a low risk for intracerebral hemorrhage $(<1 \%$ per year $)$; asymptomatic 
TABLE 1. Summary of patient characteristics*

\begin{tabular}{|c|c|c|c|c|c|c|c|}
\hline $\begin{array}{c}\text { Case } \\
\text { No. }\end{array}$ & Presentation & Sex, Age† & Location & Borden Class & Angiographic Outcome at FU & FU Length (mos) & Clinical Outcome \\
\hline 1 & $\mathrm{IPH}$ & M, 65 & Lt tentorial & III & No recurrence & 6 & Improved \\
\hline 2 & Incidental & $\mathrm{F}, 41$ & Lt TS & III & No recurrence & 8 & Stable \\
\hline 3 & $\mathrm{SAH}$ & $M, 46$ & Vein of Galen \& SVP & III & NA & NA & NA \\
\hline 4 & PT & M, 74 & Rt TSS & III & No recurrence & 7 & Improved \\
\hline 5 & $\mathrm{IPH}$ & $M, 68$ & Lt occipital & III & No recurrence & 36 & Improved \\
\hline 6 & Incidental & $M, 58$ & Tentorial & III & No recurrence & 6 & Stable \\
\hline 7 & Incidental & $\mathrm{M}, 18$ & Rt temporal & III & No recurrence & 6 & Stable \\
\hline 8 & $\mathrm{SDH}$ & $M, 67$ & SSS & III & NA & NA & NA \\
\hline 9 & Incidental & $F, 65$ & Lt TS & III & No recurrence & 14 & Stable \\
\hline 10 & Incidental & $\mathrm{F}, 41$ & Tentorial & III & Recurred after 8 mos & 24 & Stable \\
\hline 11 & Dizziness, vertigo & $\mathrm{M}, 66$ & Clivus & III & No recurrence & 6 & Improved \\
\hline 12 & Proptosis & $\mathrm{F}, 6 \mathrm{mos}$ & Rt TS & III & No recurrence & 12 & Improved \\
\hline 13 & PT & $M, 58$ & Rt TS & III & Recurred after 24 mos & 24 & Stable \\
\hline 14 & Incidental & $M, 59$ & Lt falcotentorial & III & No recurrence & 7 & Stable \\
\hline 15 & $\mathrm{IPH}$ & $M, 68$ & Lt occipital & III & No recurrence & 33 & Improved \\
\hline 16 & PT & $\mathrm{F}, 67$ & Rt TSS & III & Recurred after 24 mos & 24 & Stable \\
\hline 17 & Incidental & $F, 59$ & SSS & III & No recurrence & 39 & Stable \\
\hline 18 & Incidental & $\mathrm{F}, 81$ & Lt TS & III & NA & NA & Stable \\
\hline 19 & PT & $F, 60$ & Lt TSS & III & Cured & 15 & Stable \\
\hline 20 & Headache, bruit & M, 19 & Rt TS & III & No recurrence & 6 & Improved \\
\hline 21 & Ataxia & M, 76 & Foramen magnum & III & No recurrence & 2 & Stable \\
\hline 22 & $\mathrm{IPH}$ & $\mathrm{F}, 64$ & Rt frontoparietal & III & No recurrence & 6 & Improved \\
\hline 23 & $\mathrm{IPH}$ & $\mathrm{F}, 49$ & Tentorial & III & No recurrence & 8 & Improved \\
\hline 24 & Incidental & $\mathrm{M}, 71$ & Rt parietal & III & No recurrence & 6 & Improved \\
\hline 25 & Myelopathy & M, 83 & SVP & V & NA & NA & NA \\
\hline 26 & IPH & $F, 75$ & Lt TSS & III & NA & NA & NA \\
\hline
\end{tabular}

$\mathrm{FU}=$ follow-up; $\mathrm{IPH}$ = intraparenchymal hemorrhage; $\mathrm{NA}$ = not available; $\mathrm{PT}$ = pulsatile tinnitus; $\mathrm{SAH}$ = subarachnoid hemorrhage; $\mathrm{SDH}=$ subdural hemorrhage; $\mathrm{SSS}$ = superior sagittal sinus; SVP = spinal venous plexus; TS = transverse sinus; TSS = transverse-sigmoid sinus.

* Angiographic results at last treatment showed that all patients were "cured."

$\dagger$ Age in years except where otherwise indicated.

Types II and III lesions with CVD carry an intermediate risk for bleed (1.4\%-1.5\% per year), and symptomatic Types II and III fistulas with CVD have a high risk of hemorrhage (7.4\%-7.6\% per year). ${ }^{14}$

DAVFs can be treated by 3 modalities: surgery, endovascular embolization, or stereotactic radiosurgery (SRS). Lucas et al. performed a meta-analysis of the various treatment options for DAVFs. ${ }^{10}$ They observed that in transverse-sigmoid sinus DAVFs, combined therapy (endovascular plus surgical treatment) proved significantly more effective than either therapy alone $(\mathrm{p}<0.01)$. For lesions of the tentorial incisura, combined therapy and surgical obliteration alone proved superior to embolization ( $p<0.001)$. For carotid-cavernous fistulas, treatment was primarily endovascular, with success rates of $62 \%$ and $78 \%$ for transarterial and transvenous approaches, respectively. For anterior fossa (ethmoidal) DAVFs, surgical obliteration was highly effective, with a success rate of $95 \%$. The authors concluded that there was no single ideal treatment for DAVFs and that each patient should be managed individually. ${ }^{10}$ In a systematic review of SRS for
DAVFs, complete obliteration was observed in 56\% and $75 \%$ of patients with and without cortical venous reflux, respectively. SRS may be a safe alternative for recurrent or refractory DAVFs. ${ }^{5}$

Endovascular embolization with Onyx is effective, especially in complex fistulas. The advantage of Onyx is that it gradually precipitates in a radial fashion from outside inward, forming a radial cast. This creates a patent channel in the center of the cast that allows the Onyx to be injected slowly and accurately. The injection can be interrupted several times throughout the procedure to assess the extent of embolization. ${ }^{8}$ Penetration and occlusion of the fistulous point and common venous outlet must occur for cure to be achieved. Failure to cast the fistula into the venous side can lead to late recurrence as observed in 1 case in the present study. In the other 2 cases that recurred and in which the Onyx cast reached the proximal portion of the common vein, we hypothesize that the cast may not have completely filled and occluded the lumen of the venous outlet. Absence of early venous drainage on the immediate postembolization angiogram may have 

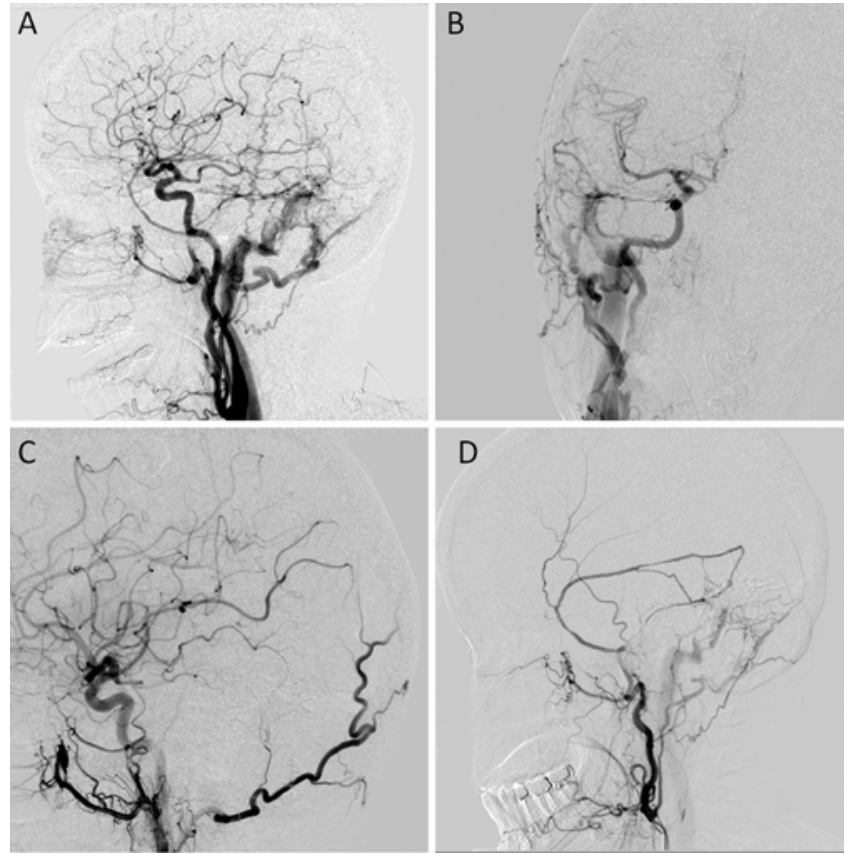

D

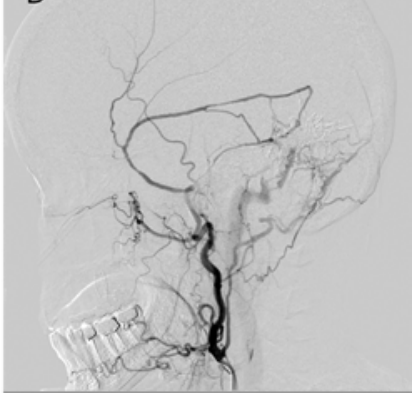

FIG. 2. Angiograms obtained in a 58-year-old man with a DAVF of the right transverse-sigmoid sinus. A and B: Angiograms obtained before treatment showing the fistula fed by right middle meningeal and occipital arteries and draining into the transverse-sigmoid sinus. C: Angiogram obtained immediately after treatment showing complete disappearance of the venous outlet. D: Angiogram obtained at the $24-$ month follow-up showing recurrence of the fistula.

been related to significant slowing of flow though the fistula rather than an actual cure. Incomplete casting with Onyx, and thus persistence of venous outlet, may have led to delayed recurrence of the fistula. Hence, it is essential to follow these patients closely with serial angiography for the first 2 years.

Our study has several limitations. It is a retrospective, single-institution study involving a small cohort of patients. Angiographic follow-up was available in only $80.7 \%$ of the patients. However, despite the limited follow-

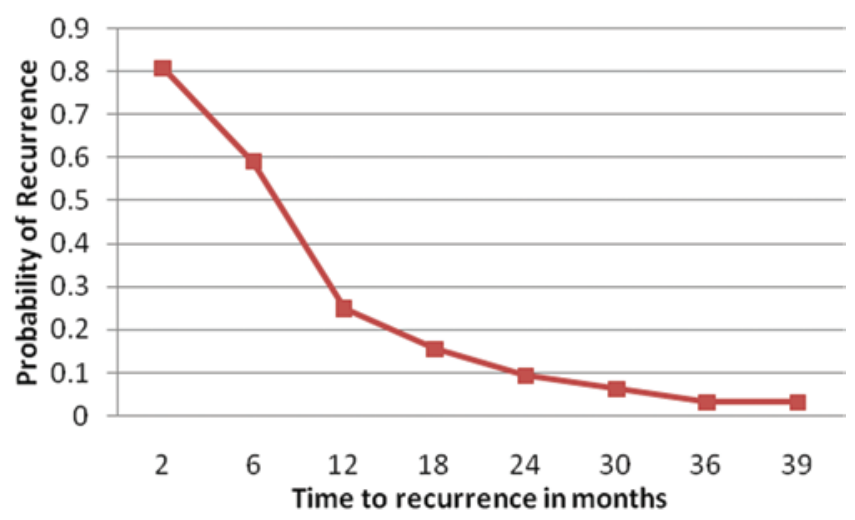

FIG. 3. Kaplan-Meier graph showing the time to recurrence. The probability of recurrence is high in the 1st year after treatment, beyond which the probability of recurrence steeply decreases and is very low after 24 months of treatment. Figure is available in color online only. up, $14.3 \%$ of our patients with relatively long-term followup were found to have a recurrence. Thus, this is actually an underestimation of the true incidence of recurrence. Perhaps a more thorough follow-up may have yielded a better estimate of true recurrence rates following endovascular embolization.

\section{Conclusions}

Recurrence following initial angiographic cure of DAVF is not uncommon. Incomplete penetration of the embolic material into the proximal portion of the venous outlet may lead to delayed recurrence. Long-term angiographic follow-up is highly recommended.

\section{References}

1. Adamczyk P, Amar AP, Mack WJ, Larsen DW: Recurrence of "cured" dural arteriovenous fistulas after Onyx embolization. Neurosurg Focus 32(5):E12, 2012

2. Awad IA, Little JR, Akarawi WP, Ahl J: Intracranial dural arteriovenous malformations: factors predisposing to an aggressive neurological course. J Neurosurg 72:839-850, 1990

3. Borden JA, Wu JK, Shucart WA: A proposed classification for spinal and cranial dural arteriovenous fistulous malformations and implications for treatment. J Neurosurg 82:166-179, 1995

4. Brown RD Jr, Wiebers DO, Nichols DA: Intracranial dural arteriovenous fistulae: angiographic predictors of intracranial hemorrhage and clinical outcome in nonsurgical patients. $\mathbf{J}$ Neurosurg 81:531-538, 1994

5. Chen CJ, Lee CC, Ding D, Starke RM, Chivukula S, Yen $\mathrm{CP}$, et al: Stereotactic radiosurgery for intracranial dural arteriovenous fistulas: a systematic review. J Neurosurg 122:353-362, 2015

6. Cognard C, Gobin YP, Pierot L, Bailly AL, Houdart E, Casasco A, et al: Cerebral dural arteriovenous fistulas: clinical and angiographic correlation with a revised classification of venous drainage. Radiology 194:671-680, 1995

7. De Keukeleire K, Vanlangenhove P, Kalala Okito J-P, Hallaert G, Van Roost D, Defreyne L: Transarterial embolization with ONYX for treatment of intracranial non-cavernous dural arteriovenous fistula with or without cortical venous reflux. J Neurointerv Surg 3:224-228, 2011

8. Elhammady MS, Wolfe SQ, Ashour R, Farhat H, Moftakhar $\mathrm{R}$, Lieber BB, et al: Safety and efficacy of vascular tumor embolization using Onyx: is angiographic devascularization sufficient? J Neurosurg 112:1039-1045, 2010

9. Hu YC, Newman CB, Dashti SR, Albuquerque FC, McDougall CG: Cranial dural arteriovenous fistula: transarterial Onyx embolization experience and technical nuances. J Neurointerv Surg 3:5-13, 2011

10. Lucas CP,Zabramski JM, Spetzler RF, Jacobowitz R: Treatment for intracranial dural arteriovenous malformations: a meta-analysis from the English language literature. Neurosurgery 40:1119-1132, 1997

11. Newton TH, Cronqvist S: Involvement of dural arteries in intracranial arteriovenous malformations. Radiology 93:1071-1078, 1969

12. Nogueira RG, Dabus G, Rabinov JD, Eskey CJ, Ogilvy CS, Hirsch JA, et al: Preliminary experience with onyx embolization for the treatment of intracranial dural arteriovenous fistulas. AJNR Am J Neuroradiol 29:91-97, 2008

13. van Dijk JM, Willinsky RA: Venous congestive encephalopathy related to cranial dural arteriovenous fistulas. Neuroimaging Clin N Am 13:55-72, 2003 
14. Zipfel GJ, Shah MN, Refai D, Dacey RG Jr, Derdeyn CP: Cranial dural arteriovenous fistulas: modification of angiographic classification scales based on new natural history data. Neurosurg Focus 26(5):E14, 2009

\section{Disclosure}

The authors report no conflict of interest concerning the materials or methods used in this study or the findings specified in this paper.

\section{Author Contributions}

Conception and design: Elhammady, Ambekar, Gaynor. Acquisi- tion of data: Ambekar, Gaynor. Analysis and interpretation of data: all authors. Drafting the article: Elhammady, Ambekar, Peterson. Critically revising the article: Elhammady, Ambekar, Peterson. Reviewed submitted version of manuscript: all authors. Approved the final version of the manuscript on behalf of all authors: Elhammady. Statistical analysis: all authors. Administrative/technical/material support: all authors. Study supervision: Elhammady, Peterson.

\section{Correspondence}

Mohamed Samy Elhammady, University of Miami Miller School of Medicine, Department of Neurological Surgery, Lois Pope LIFE Center, 1095 N.W. 14th Terrace (D4-6), Miami, FL 33136. email: melhammady2@med.miami.edu. 